\title{
Four cases of endophthalmitis after 25-gauge pars plana vitrectomy
}

This article was published in the following Dove Press journal:

Clinical Ophthalmology

27 August 2012

Number of times this article has been viewed

\section{Tetsuya Mutoh \\ Koji Kadoya \\ Makoto Chikuda}

Department of Ophthalmology, Dokkyo Medical University Koshigaya

Hospital, Koshigaya, Saitama, Japan
Correspondence: Tetsuya Mutoh Department of Ophthalmology, Dokkyo Medical University Koshigaya Hospital, Koshigaya, Saitama 343-8555, Japan Tel +8I 48965 I I I I

Fax +8| 48965 | | 27

Email mtetsuya@dokkyomed.ac.jp
Abstract: We report our recent experience with four cases of endophthalmitis (one male, three females) after 25-gauge pars plana vitrectomy (PPV). One was a case of persistent cystoid macular edema caused by branch retinal vein occlusion, whereas the remaining three were cases of epiretinal membrane. Preoperative antibiotics before the first PPV procedure were not administered in three of the four cases. Endophthalmitis occurred 2-4 days after the first procedure in all cases, for which ceftazidime $2.0 \mathrm{mg} / 0.1 \mathrm{~mL}$ and vancomycin $1.0 \mathrm{mg} / 0.1 \mathrm{~mL}$ were injected into the vitreous cavity. This was followed by emergent 20-gauge PPV and intraocular lens removal using an infusion fluid containing ceftazidime and vancomycin. After the second PPV procedure, progress was good in three cases while retinal detachment occurred in the remaining case one month after surgery; this case required a third PPV procedure. Final best-corrected visual acuity ranged from 20/100 to 20/25 for the four cases. Bacterial cultures were negative after the second PPV procedure in all cases. In conclusion, postoperative endophthalmitis occurred in four of 502 cases $(0.80 \%)$ that underwent 25 -gauge PPV at our hospital. It is important to minimize the incidence of endophthalmitis after 25-gauge PPV.

Keywords: 25 -gauge pars plana vitrectomy, endophthalmitis, incidence

\section{Introduction}

Recent advances in retinal surgery techniques and instrumentation, such as 25-gauge pars plana vitrectomy (PPV), have permitted the use of sutureless vitrectomy through small, self-sealing, transconjunctival wounds, allowing patients to recover more quickly and comfortably. ${ }^{1}$ In earlier years, surgical intervention was limited to diseases that could be treated by core vitrectomy, such as epiretinal membrane and retinal vein occlusion. Recently, surgical intervention has become possible for diseases such as proliferative diabetic retinopathy and retinal detachment. ${ }^{2}$

The potential for development of postoperative endophthalmitis after 25-gauge PPV must always be considered because the procedure does not include removal of the peripheral vitreous humor. In addition, because the scleral incision is not sutured, the vitreous humor is exposed. ${ }^{3}$ Scoot et al reported a higher rate of postoperative endophthalmitis with 25-gauge PPV than with 20-gauge PPV. ${ }^{4}$

Endophthalmitis is a serious surgical complication. The incidence of endophthalmitis must be minimized by employing minimally invasive vitrectomy procedures. We report four cases of endophthalmitis after 25-gauge PPV performed by the same surgeon at Dokkyo Medical University Koshigaya Hospital. The 25-gauge PPV procedure was introduced in August 2004 at our hospital. Since then, 502 cases have been treated by the same surgeon up to December 2010. 


\section{Case report I}

A 65-year-old woman with bilateral pseudophakia presented with cystoid macular edema caused by branch retinal vein occlusion in the right eye. Best-corrected visual acuity was $20 / 25$ in the right eye and 20/20 in the left eye. Although retinal photocoagulation was performed, cystoid macular edema persisted. PPV was planned to reduce cystoid macular edema. Preoperative topical antibiotics were not administered.

\section{First PPV procedure}

PPV (25-gauge) was performed in the right eye using an Accurus 800CS vitrectomy system (Alcon Surgical, Kanto Chemical, Tokyo, Japan) and infusion fluid (BSS Plus; Alcon Surgical) that was devoid of any antibiotics on August 3, 2009. At a site $4.0 \mathrm{~mm}$ from and parallel to the limbus, a trocar was inserted at a $30^{\circ}$ angle, creating a tunnel sclerotomy. The conjunctiva was slightly displaced to the corneal side. Posterior vitreous detachment had already occurred at the time of surgery. At the completion of surgery, a triangular surgical spear was used to check for vitreous prolapse at all three ports. Only one incision was sutured because of leakage. Triamcinolone was not used during the procedure, which took 7 minutes to complete. Subconjunctival antibiotic was not injected after completion of surgery.

\section{Progress after first PPV procedure}

On postoperative day 1, fundus visibility was good. On postoperative day 2 , the anterior chamber became severely inflamed, and fibrin and hypopyon were evident. The fundus was not visible. Intraocular pressure in the right eye was $32 \mathrm{mmHg}$. Acute postoperative bacterial endophthalmitis was suspected. Ceftazidime $2.0 \mathrm{mg} / 0.1 \mathrm{~mL}$ and vancomycin $1.0 \mathrm{mg} / 0.1 \mathrm{~mL}$ were injected into the vitreous cavity. Culture was not performed before the first antibiotic injection. On postoperative day 3, emergent 20-gauge PPV and intraocular lens removal were performed for the remaining anterior capsule. An infusion fluid containing ceftazidime $2.0 \mathrm{mg} / 0.1 \mathrm{~mL}$ and vancomycin $1.0 \mathrm{mg} / 0.1 \mathrm{~mL}$ was utilized this time.

\section{Progress after second PPV procedure}

Inflammation decreased promptly. Bacterial cultures from the intraocular lens were negative. The intraocular lens was implanted on the anterior capsule 17 months after the second PPV procedure. Final best-corrected visual acuity was 20/30 2 years after the second PPV procedure.

\section{Case report 2}

A 62-year-old phakic woman was admitted to our hospital with epiretinal membrane in the right eye. Best-corrected visual acuity was 20/200 in the right eye and 20/20 in the left eye. Preoperative topical antibiotics were not administered.

\section{First PPV procedure}

After temporal corneal incision cataract surgery, 25-gauge PPV with indocyanine green-assisted epiretinal and internal limiting membrane peeling were performed in the right eye on October 20, 2006. At the completion of the surgery, we checked that there was no leakage at any of the three ports. All incisions were not sutured and subconjunctival antibiotic was not injected after completion of the surgery. Operating time was 36 minutes.

\section{Progress after first PPV procedure}

On the morning of postoperative day 3 , severe inflammation and fibrin were observed in the anterior chamber. The fundus was not visible. Acute postoperative bacterial endophthalmitis was suspected. Ceftazidime $2.0 \mathrm{mg} / 0.1 \mathrm{~mL}$ and vancomycin $1.0 \mathrm{mg} / 0.1 \mathrm{~mL}$ were injected into the vitreous cavity, and emergent 20-gauge PPV and intraocular lens removal were performed the same day. An infusion fluid containing ceftazidime $2.0 \mathrm{mg} / 0.1 \mathrm{~mL}$ and vancomycin $1.0 \mathrm{mg} / 0.1 \mathrm{~mL}$ was utilized during PPV. At the end of the procedure, endolaser photocoagulation was performed around the retinal vein occlusion.

\section{Progress after second PPV procedure}

Inflammation resolved promptly after surgery. Bacterial cultures from the intraocular lens and the vitreous body were negative. Scleral fixation of the intraocular lens was performed 6 months after the second PPV procedure. Final best-corrected visual acuity was 20/100 10 months after the second procedure.

\section{Case report 3}

A 70-year-old phakic woman was admitted to our hospital with epiretinal membrane in the left eye. Best-corrected visual acuity was 20/16 in the right eye and 20/20 in the left eye. Preoperative topical antibiotics were not administered.

\section{First PPV procedure}

After temporal corneal incision cataract surgery, 25-gauge triamcinolone-assisted PPV with indocyanine green-assisted epiretinal and internal limiting membrane peeling were 
performed in the left eye on December 8, 2005. Operating time was 61 minutes. All incisions were not sutured and subconjunctival antibiotic was not injected after completion of surgery.

\section{Progress after first PPV procedure}

On postoperative day 3 , severe inflammation was observed in the anterior chamber, and fibrin and hypopyon were evident. The fundus was visible but unclear. Acute postoperative bacterial endophthalmitis was suspected. Ceftazidime $2.0 \mathrm{mg} / 0.1 \mathrm{~mL}$ and vancomycin $1.0 \mathrm{mg} / 0.1 \mathrm{~mL}$ were injected into the vitreous cavity on postoperative day 4 , and emergent 20 -gauge PPV and intraocular lens removal were performed on postoperative day 5 . An infusion fluid containing ceftazidime $2.0 \mathrm{mg} / 0.1 \mathrm{~mL}$ and vancomycin $1.0 \mathrm{mg} / 0.1 \mathrm{~mL}$ was utilized during PPV. At the end of the procedure, endolaser photocoagulation was performed around the retinal vein occlusion.

\section{Progress after second PPV procedure}

Inflammation resolved promptly after surgery. Bacterial cultures from the intraocular lens and vitreous body were negative. Scleral fixation of the intraocular lens was performed 4 years after the second PPV procedure. Final bestcorrected visual acuity was 20/20 4 years and 5 months after the second procedure.

\section{Case report 4}

A 65-year-old phakic man was admitted to our hospital with epiretinal membrane in the left eye (Figures 1 and 2). Best-corrected visual acuity was 20/16 in the right eye and

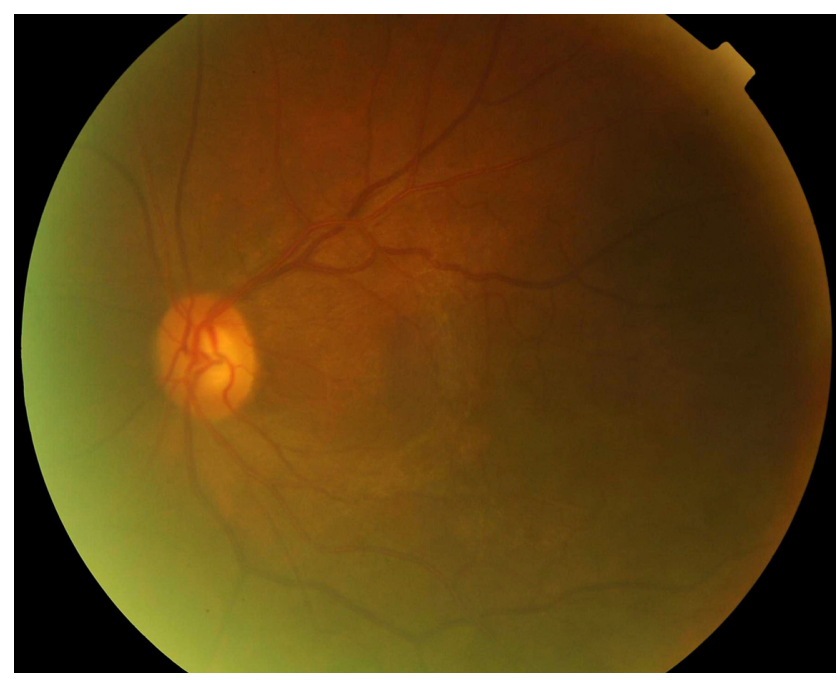

Figure I An image of the fundus on initial presentation in case 4. The epiretinal membrane is evident over the macula.
$20 / 40$ in the left eye. Topical levofloxacin was administered 4 times/day 24 hours before surgery in this case.

\section{First PPV procedure}

After temporal corneal incision cataract surgery, 25-gauge triamcinolone-assisted PPV with epiretinal membrane peeling was performed in the left eye on October 15, 2009. Operating time was 25 minutes. All incisions were not sutured and subconjunctival antibiotic was not injected after completion of surgery.

\section{Progress after first PPV procedure}

On postoperative day 4, severe inflammation was observed in the anterior chamber, and fibrin and hypopyon were evident (Figure 3). The fundus was not visible. Acute postoperative bacterial endophthalmitis was suspected. Ceftazidime $2.0 \mathrm{mg} / 0.1 \mathrm{~mL}$ and vancomycin $1.0 \mathrm{mg} / 0.1 \mathrm{~mL}$ were injected into the vitreous cavity, and emergent 20 -gauge PPV and intraocular lens removal were performed on postoperative day 5. An infusion fluid containing ceftazidime $2.0 \mathrm{mg} / 0.1 \mathrm{~mL}$ and vancomycin $1.0 \mathrm{mg} / 0.1 \mathrm{~mL}$ was utilized during PPV.

\section{Other PPV procedures}

Inflammation resolved slowly after surgery. However, retinal detachment occurred one month after the procedure. Emergent 20-gauge PPV, endolaser photocoagulation, and air tamponade were performed furthermore. Final best-corrected visual acuity was 20/20 4 years and 5 months after the second PPV procedure. Inflammation resolved promptly after the third surgery, and best-corrected visual acuity improved to 20/25 3 weeks at this time. Scleral fixation of the intraocular lens was not performed at the patient's request. Aphakia remained for 8 months after the third PPV procedure.

\section{Discussion}

Here we report four cases of endophthalmitis after 25-gauge PPV performed by the same surgeon at our institution. The 25-gauge PPV procedure was introduced in August 2004 at our hospital. Since then, 502 cases have been treated by the same surgeon up to December 2010. The rate of endophthalmitis after 25 -gauge PPV was $0.80 \%$ during this time period (four of 502 eyes). Hu et al ${ }^{1}$ reported an endophthalmitis incidence rate of $0.07 \%$ after 25-gauge PPV (one of 1424 eyes). Other reports include those of Scott et $\mathrm{al}^{4}(0.84 \% ; 11$ of 1307 eyes), Shimada et al ${ }^{5}(0.03 \%$; one of 3343 eyes $)$, and Chen et $\mathrm{al}^{6}(0.23 \%$; one of 431 eyes). The rate observed in our institution was similar to that in the study by Scott et al. ${ }^{4}$ 


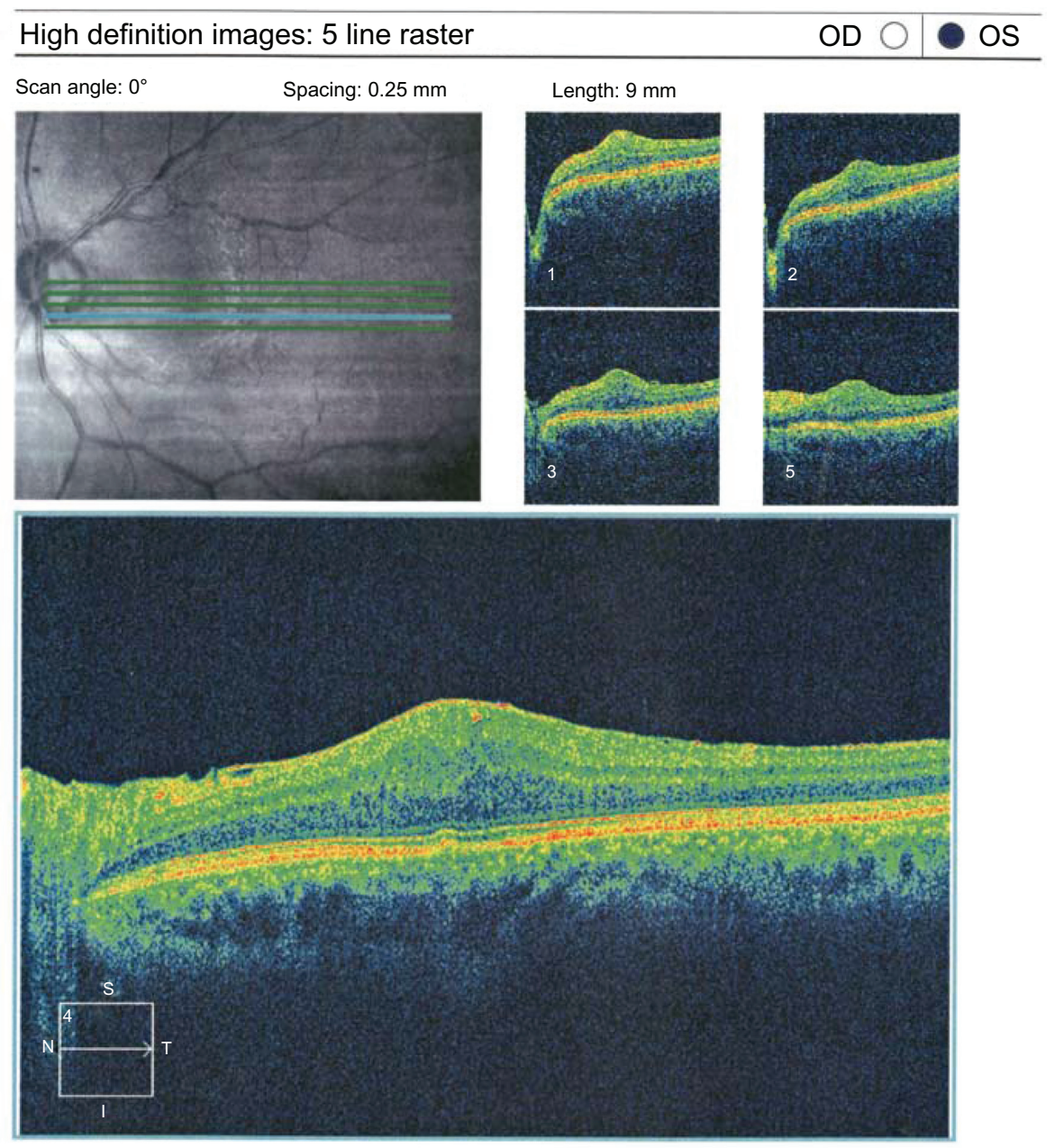

Figure 2 Optical coherence tomography findings on initial presentation of case 4. Retinal thickening and epiretinal membrane are evident.

Interestingly, four cases of endophthalmitis after 20-gauge PPV occurred during the same time period in our institution. However, direct comparison of cases treated with 20-gauge PPV and those treated with 25-gauge PPV was impossible because of differences in surgeons and underlying diseases.

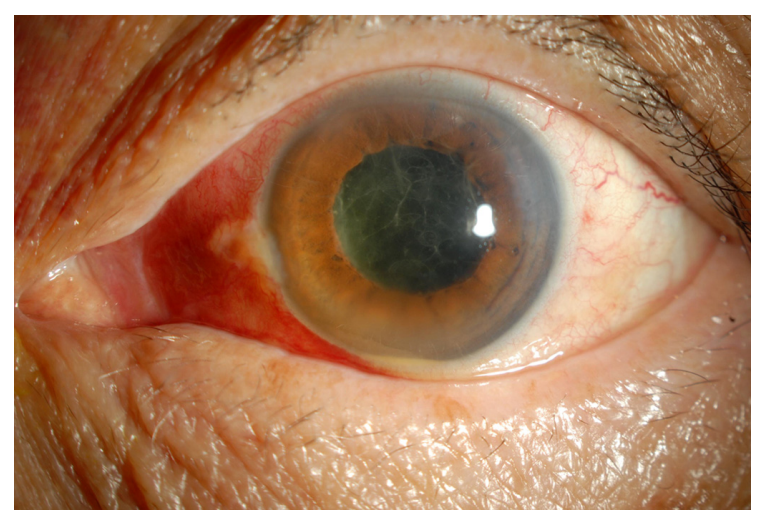

Figure 3 An image of the anterior chamber of case 4 on postoperative day 4 . Hypopyon and fibrin have developed in the anterior chamber.
To decrease the rate of endophthalmitis after 25 -gauge PPV, adequate suturing of the three ports of the corneal wound is imperative. Although sutureless vitrectomy is one of the benefits of 25 -gauge PPV, it is not always effective in eliminating the risk of endophthalmitis. As recommended by Shimada et al, ${ }^{7}$ irrigation of the operative field with $5 \mathrm{~mL}$ of $1.25 \%$ povidone-iodine at the start of surgery should become mandatory during all future PPV procedures. ${ }^{7}$ Using this method, Shimada et $\mathrm{al}^{7}$ reported no cases of endophthalmitis after 25-gauge PPV (0 of 1546 eyes).

In addition, preoperative and postoperative administration of antibiotics can reduce the incidence of endophthalmitis. Preoperative administration of antibiotics may significantly decrease the bacterial count before surgery. ${ }^{8}$ In this study, topical levofloxacin was administered preoperatively in only one of the reported cases (case 4). However, the effect of preoperative administration of antibiotics on postoperative incidence of endophthalmitis remains unclear. ${ }^{8}$ 
Postoperative care is also important. Several ophthalmic medications are applied simultaneously in our hospital. Although the conjunctival sac can store only about $7 \mu \mathrm{L}$, one drop of medication is approximately $40 \mu \mathrm{L}$ and requires about 5 minutes for absorption. ${ }^{9}$ Absorption may be compromised when multiple medications are administered simultaneously. This practice may result in postoperative development of endophthalmitis.

Fungal endophthalmitis has been reported to occur after triamcinolone-assisted PPV with injection of triamcinolone into the vitreous cavity at the end of surgery. ${ }^{10}$ Infectious endophthalmitis has also been reported to occur after triamcinolone-assisted anterior vitrectomy. ${ }^{11}$ In contrast, Sakamoto et al reported an infectious endophthalmitis incidence of 0.053\% after triamcinolone-assisted PPV; this incidence did not differ from that after PPV without triamcinolone. ${ }^{12}$ Unlike the study by Ataka et $\mathrm{al}^{10}$ triamcinolone was used solely to visualize the vitreous cavity in cases 3 and 4 reported here. Most of the triamcinolone was aspirated and removed during PPV. This procedure must be performed cautiously, and patients should be carefully followed to avoid possible development of postoperative endophthalmitis.

No bacteria were detected in the four cases reported here. $\mathrm{Hu}$ et $\mathrm{al}^{1}$ and $\mathrm{Chen}$ et $\mathrm{al}^{6}$ reported that pathological bacteria were not detected in their cases of endophthalmitis after 25-gauge PPV. In the event that bacterial strains are identified, it is helpful to select the appropriate antibiotics for treatment. However, we have to take it into consideration using antibiotics even though bacteria are not detected.

Despite the development of endophthalmitis after 25 -gauge PPV in the cases reported here, none of the cases lost their eyesight. Final visual acuity was good in all cases. However, the incidence of endophthalmitis after 25-gauge PPV was higher in this study than in the studies of $\mathrm{Hu}$ et $\mathrm{al}^{1}$ and Shimada et al. ${ }^{5}$ The main goal for the Department of Ophthalmology at our institution is to decrease the incidence of this condition further until it becomes negligible.

Clinical Ophthalmology

\section{Publish your work in this journal}

Clinical Ophthalmology is an international, peer-reviewed journal covering all subspecialties within ophthalmology. Key topics include: Optometry; Visual science; Pharmacology and drug therapy in eye diseases; Basic Sciences; Primary and Secondary eye care; Patient Safety and Quality of Care Improvements. This journal is indexed on

\section{Acknowledgment}

The authors would like to thank Enago (www.enago.jp) for the English language review.

\section{Disclosure}

The authors report no conflicts of interest in this work.

\section{References}

1. Hu AY, Bourges JL, Shah SP, et al. Endophthalmitis after pars plana vitrectomy: a 20- and 25-gauge comparison. Ophthalmology. 2009; 116(7):1360-1365.

2. Shimada H, Nakashizuka H, Mori R, Mizutani Y. Expanded indications for 25-gauge transconjunctival vitrectomy. Jpn J Ophthalmol. 2005; 49(5):397-401.

3. Matsuyama K, Kunitomi K, Taomoto M, Nishimura T. Early-onset endophthalmitis caused by methicillin-resistant Staphylococcus epidermidis after 25-gauge transconjunctival sutureless vitrectomy. Jpn J Ophthalmol. 2008;52(6):508-510.

4. Scott IU, Flynn HW Jr, Dev S, et al. Endophthalmitis after 25-gauge and 20-gauge pars plana vitrectomy: incidence and outcomes. Retina. 2008;28(1):138-142.

5. Shimada H, Nakashizuka H, Hattori T, Mori R, Mizutani Y, Yuzawa M. Incidence of endophthalmitis after 20- and 25-gauge vitrectomy causes and prevention. Ophthalmology. 2008;115(12):2215-2220.

6. Chen JK, Khurana RN, Nguyen QD, Do DV. The incidence of endophthalmitis following transconjunctival sutureless 25-vs 20-gauge vitrectomy. Eye (Lond). 2009;23(4):780-784.

7. Shimada H, Nakashizuka H, Hattori T, Mori R, Mizutani Y, Yuzawa M. Effect of operative field irrigation on intraoperative bacterial contamination and postoperative endophthalmitis rates in 25-gauge vitrectomy. Retina. 2010;30(8):1242-1249.

8. Ohashi Y. Meaning of the eye administration of the preoperative antibiotics from endophthalmitis suit. Jpn J Ophthalmol Soc. 2004; 108(2):129-131.

9. Maruo T, Honda K, Usui M, Tano Y. Eye administration. Gankagaku. Bunkodo, Tokyo, Japan. 2002:1:999.

10. Ataka S, Kurita K, Wada S, Tayeya K, Shiraki K. A case of mycotic endophthalmitis after triamcinolone acetonide-assisted pars plana vitrectomy. Int Ophthalmol. 2007;27(1):51-54.

11. Lee SM, Shin YJ, Park KH. Postoperative infectious endophthalmitis after triamcinolone-assisted anterior vitrectomy. J Cataract Refract Surg. 2007;33(4):731-732.

12. Sakamoto T, Enaida H, Kubota $T$, et al. Incidence of acute endophthalmitis after triamcinolone-assisted pars plana vitrectomy. Am J Ophthalmol. 2004;138(1):137-138.

PubMed Central and CAS, and is the official journal of The Society of Clinical Ophthalmology (SCO). The manuscript management system is completely online and includes a very quick and fair peer-review system, which is all easy to use. Visit http://www.dovepress.com/ testimonials.php to read real quotes from published authors. 